\title{
THE
}

\section{Prescribing of Antipsychotic Medication in a Medicaid Population: Use of Polytherapy and Off-Label Dosages}

\author{
Robert L. Dufresne \\ University of Rhode Island, robdufresne@uri.edu \\ J. Kogut \\ University of Rhode Island \\ Felix Yam
}

Follow this and additional works at: https://digitalcommons.uri.edu/php_facpubs

Terms of Use

All rights reserved under copyright.

\section{Citation/Publisher Attribution}

Kogut, S. J., Yam, F., \& Dufresne, R. (2005). Prescribing of Antipsychotic Medication in a Medicaid Population: Use of Polytherapy and Off-Label Dosages. Journal of Managed Care Pharmacy. 11(1), 17-24. doi: 10.18553/jmcp.2005.11.1.17

Available at: http://dx.doi.org/10.18553/jmcp.2005.11.1.17

This Article is brought to you for free and open access by the Pharmacy Practice at DigitalCommons@URI. It has been accepted for inclusion in Pharmacy Practice Faculty Publications by an authorized administrator of DigitalCommons@URI. For more information, please contact digitalcommons-group@uri.edu. 


\title{
Prescribing of Antipsychotic Medication in a Medicaid Population: Use of Polytherapy and Off-Label Dosages
}

\author{
STEPHEN J. KOGUT, PhD, MBA; FELIX YAM, PharmD; and ROBERT DUFRESNE, PhD, PhD, BCPS, BCPP
}

\begin{abstract}
OBJECTIVES: To describe the use of atypical antipsychotic medications in a Medicaid-enrolled population composed primarily of elderly and disabled patients. Our analyses focused upon the frequency of use of polytherapy with multiple antipsychotic medications and the prescribing of off-label dosages.

METHODS: We conducted a cross-sectional retrospective analysis of oral antipsychotic medication use, as prescribed for this population in 2003. The unit of analysis was the patient. We determined the prevalence of use of each type of antipsychotic medication according to gender and age group and determined the extent of use of combination therapies with multiple oral antipsychotic medications. Using the dosage ranges described in the product labeling, we identified the percentage of patients prescribed in-range dosages, overall and for each atypical antipsychotic medication studied. Those identified as receiving out-of-range (off-label) dosages were further stratified by gender and age group. The statistical significance of differences between these proportions was assessed using the chi-square test.

RESULTS: Of the 8,616 patients meeting our inclusion criteria, 7,748 (90\%) received monotherapy with an oral antipsychotic medication and 868 patients $(10 \%)$ received polytherapy with multiple oral antipsychotic medications. Approximately 2 of 3 patients receiving atypical antipsychotic medications were prescribed a dosage that was within the range recommended in the product labeling. Dosages lower than recommended in the product labeling were prescribed for $27 \%$ of patients receiving atypical antipsychotics, while $6 \%$ of patients received an above-range dosage. The frequency of patients receiving in-range dosages varied substantially among medications. Younger patients and male patients were more frequently prescribed above-range dosages while older patients and female patients were more frequently prescribed below-range dosages of these medications ( $P<0.001$ for both findings).

CONCLUSION: In this subpopulation of Medicaid enrollees who were prescribed antipsychotic medications, we found a $10 \%$ incidence of use of antipsychotic polytherapy and a $33 \%$ incidence of prescribing of dosages outside the range listed in the product labeling. These findings suggest that physicians commonly prescribe antipsychotic medications in a manner that differs from the recommendations described in the prescribing information. The off-label use of atypical antipsychotic medications raises important questions regarding the purpose and applicability of the product labeling and the role and ability of the pharmacist to provide information regarding the risks and benefits of therapy as commonly prescribed.
\end{abstract}

KEYWORDS: Antipsychotic, Atypical, Off-label, Polytherapy, Dosage, Prescribing

J Manag Care Pharm. 2005:11(1):17-24
T he atypical antipsychotic medications have rapidly become a leading drug expense category within Medicaid populations, which typically serve lowerincome citizens, institutionalized seniors, and the disabled. Many patients within this population have psychiatric illnesses for which antipsychotic medications are commonly prescribed. The U.S. Food and Drug Administration (FDA) has approved the atypical antipsychotic medications for use in the treatment of schizophrenia (all atypicals) and bipolar disease (olanzapine, risperidone, and ziprasidone only), yet these agents are commonly prescribed "off-label" for a variety of other conditions, particularly where psychosis is a feature.

Despite a substantial difference in the direct cost of these medications compared with the conventional antipsychotics, several researchers have found the atypicals to be at least as cost effective as the conventional antipsychotics. ${ }^{1-5}$ These medications also provide advantages in terms of decreased motoric side effects such as drug-induced parkinsonism, tardive dyskinesia, and akathesia ${ }^{6,7}$ and improved efficacy in treating negative symptoms of schizophrenia such as avolition (absence of initiative or motivation to begin and maintain behavior in pursuit of a goal) and flat affect. ${ }^{8-10}$ Also, the newer agents have shown advantages in terms of improvement in health-related quality of life. ${ }^{11-13}$ These medications have also been shown to be cost effective..$^{2-4,14}$ However, pharmacoeconomic studies have evaluated the cost-effectiveness of various atypical agents when administered in dosages used in clinical trials and as approved by the FDA. The cost-effectiveness of the atypical antipsychotics when used in combination therapies or when prescribed at dosages above or below the recommendations described in the product labeling has not been well studied.

While physicians may legally prescribe medication at dosages outside of the parameters recommended in the product

\section{Authors}

STEPHEN J. KOGUT, PhD, MBA, is an assistant professor, Program in Pharmacoepidemiology and Pharmacoeconomics, Department of Pharmacy Practice, and ROBERT DUFRESNE, PhD, PhD, BCPS, BCPP, is a professor and psychiatric pharmacotherapy specialist, University of Rhode Island, Kingston; FELIX YAM, PharmD, is a pharmacy practice resident, Department of Pharmacy, University of Kentucky, Lexington.

AUTHOR CORRESPONDENCE AND ARTICLE REPRINTS: Stephen J. Kogut, $\mathrm{PhD}, \mathrm{MBA}$, Department of Pharmacy Practice, University of Rhode Island, 41 Lower College Rd., Kingston, RI 02881. Tel: (401) 874-5370;

Fax: (401) 874-2181; E-mail: Kogut@URI.edu

Copyright $@ 2005$, Academy of Managed Care Pharmacy. All rights reserved. 


\begin{tabular}{|c|c|}
\hline FIGU & $\begin{array}{l}1 \text { Selection of Patients for Analyses } \\
\text { of Types of Antipsychotic Medication } \\
\text { Regimens Utilized and for Analyses } \\
\text { of Prescribed Dosages of Atypical } \\
\text { Antipsychotic Medications }\end{array}$ \\
\hline \multicolumn{2}{|l|}{$\mathrm{N}$} \\
\hline $\begin{array}{r}59,498 \\
\downarrow\end{array}$ & $\begin{array}{l}\text { Medicaid enrollees in fee-for-service component receiving at } \\
\text { least } 1 \text { prescription dispensing during } 2003\end{array}$ \\
\hline $\begin{array}{c}10,470 \\
(17.6 \%) \\
\downarrow\end{array}$ & $\begin{array}{l}\text { Patients receiving at least } 1 \text { prescription dispensing for any } \\
\text { type of antipsychotic medication }\end{array}$ \\
\hline $\begin{array}{c}8,698 \\
(14.6 \%) \\
\downarrow\end{array}$ & $\begin{array}{l}\text { Patients receiving at least } 3 \text { prescription dispensings for an oral } \\
\text { solid (excluding nonliquid) antipsychotic medication }\end{array}$ \\
\hline $\begin{array}{l}8,616 \\
(14.5 \%) \\
\downarrow\end{array}$ & $\begin{array}{l}\text { Patients who were not recently switching antipsychotic drug } \\
\text { therapy (within past } 90 \text { days) } \\
\text { - Study population for analyses of types of antipsychotic } \\
\text { medication regimens prescribed }\end{array}$ \\
\hline $\begin{array}{c}7,759 \\
(13.0 \%)\end{array}$ & $\begin{array}{l}\text { Patients who were users of risperidone, olanzapine, quetiapine, } \\
\text { aripiprazole, or ziprasidone } \\
\text { - Study population for analyses of dosages prescribed of } \\
\text { atypical antipsychotic medications }\end{array}$ \\
\hline
\end{tabular}

labeling, the safety and efficacy of a medication as evaluated by the FDA generally does not extend to off-label usage. Recent reports describing antipsychotic medication use in current practice settings reveal a high prevalence of combination therapy with multiple antipsychotic medication regimens ${ }^{15-17}$ and the use of high-dose therapies. ${ }^{18-20}$ Although randomized placebo-controlled trials are lacking, therapies that combine antipsychotic medications may hold promise for certain patient subtypes, ${ }^{21-24}$ and growing evidence suggests a benefit of high-dose therapy for some patients with treatment-resistant disease. ${ }^{25,26}$ However, studies describing the dose-response relationship pertaining to the efficacy and toxicity of the atypical antipsychotics are lacking. ${ }^{27}$

Higher dosages of atypical antipsychotic medications may provide benefit for a percentage of patients who do not respond to recommended dosages, but the risk associated with using higher dosages of an atypical antipsychotic medication has not been as well studied. Additionally, the use of below-range dosages of the atypical antipsychotics merits examination. Though prescribers may act from concern regarding the use of these potent medications in elderly or frail individuals, the use of low-dose therapy may nevertheless cause adverse effects while failing to elicit a worthwhile therapeutic response.

The objective of our study was to assess the manner in which atypical antipsychotic medications are prescribed in a Medicaid population comprising mainly elderly and disabled patients. We sought to determine the extent of use of combination oral antipsychotic therapies and the prevalence of prescribing off-label dosages. We compared dosages of the atypical antipsychotics as prescribed among older and younger patients, among genders, overall, and for specific agents. We did not presume that the prescribing of off-label dosages was inappropriate per se; rather, our aim was to better understand how these medications are prescribed and to identify opportunities for improving and studying the efficacy of the use of these medications in the population.

\section{Methods}

We conducted a cross-sectional study of antipsychotic medication use among Rhode Island Medicaid enrollees to describe the use of antipsychotic medications as most recently prescribed for patients during 2003. The state of Rhode Island provides a managed care insurance program that serves a proportion of nonsenior residents who are eligible for the program based upon low income (categorically needy). A majority of Medicaid-eligible senior and nonsenior disabled patients receive their care through a fee-for-service program component that is administered by the state's Department of Human Services. This fee-for-service population comprised the universe of patients available for our study. Our analyses were conducted solely using pharmacy claims data, which included patient age, gender, and information pertaining to the dispensed prescription. The Rhode Island Medicaid pharmacy program does not restrict the use of antipsychotic medications, nor are any particular medications considered preferred.

The unit of analysis was the patient. There were 59,498 patients enrolled in the fee-for-service component and receiving prescription medication during 2003. Seniors (aged 65 years or older) comprised $31 \%$ of the population. Among patients receiving prescription medications, $10,470(18 \%)$ received at least 1 dispensing for an oral antipsychotic medication during the study year. We chose to exclude patients who were initiating therapy and selected only those patients who received at least 3 dispensings for an oral antipsychotic medication $(n=8,761)$. This total does not include patients receiving an antipsychotic medication in liquid form $(n=1,505)$; these patients were excluded because we could not reliably calculate the dosage prescribed for liquid products given the limitations of our data source. Additionally, we excluded 63 patients who received an injectable product as their most recent dispensing of an antipsychotic medication.

We also attempted to distinguish users of combination antipsychotic therapy (polytherapy) from patients who were switching therapies. Patients were classified as users of polytherapy if they received at least 2 dispensings of the 2 different antipsychotic medications during the 90 days prior to the most recent dispensing. All other patients receiving more than 1 type of oral antipsychotic medication were considered to be recent switchers and were excluded $(n=83)$. The resulting sample 
of 8,616 patients comprised the population of study for the analyses of frequencies of use of various oral antipsychotic regimens. The sample selection criteria and totals of patients identified are presented in Figure 1.

We determined the prevalence of use of specific antipsychotic medication regimens based upon the most recent dispensing for such products occurring during the study year. Patients identified as receiving antipsychotic polytherapy were categorized as either receiving polytherapy with an atypical plus a conventional antipsychotic medication or polytherapy with 2 different atypical antipsychotic medications. The prevalence of use of polytherapy was stratified by gender and by age group (age less than 18 years, age 18 to 64 years, and age 65 years or older).

The percentage of therapies used in off-label dosage was determined for patients receiving atypical antipsychotic medications, as attributed to the dosage of the most recently dispensed prescription during the year. For this prescription, we calculated the mean daily dose by dividing the quantity of medication dispensed by the days supply received and multiplying this quotient by the strength (in milligrams) of the dispensed medication. Recommended dosages for each atypical medication were identified from the prescribing information as obtained from each manufacturer's Web site (accessed in June 2004). Where the dosage range varied by indication, age, or clinical condition, we used the lowest and highest possible range of dosages that appeared in the product labeling. FDArecommended in-range dosages as described in the product labeling were as follows-aripiprazole: 10 to $30 \mathrm{mg}$, quetiapine: 150 to $750 \mathrm{mg}$, olanzapine: 5 to $20 \mathrm{mg}$, risperidone: 1 to $8 \mathrm{mg}$, and ziprasidone: 14 to $160 \mathrm{mg}$. We did not include patients receiving clozapine in these analyses because we believed that those receiving this medication were more likely to have severe disease and/or have failed other therapies and because this medication was often dispensed in a 1-week supply, a feature that added considerable complexity to the analyses.

Several patients were prescribed "odd" dosages of medication and received different prescriptions for the same medication (e.g., $2 \mathrm{mg}$ of risperidone in the morning and $3 \mathrm{mg}$ at bedtime). Such patients were included in our analyses if the two prescriptions for different strengths of the same medication were received on the same date during the two most recent dispensings. For these 281 patients, we calculated the total dose by adding the daily dosages of the two separate prescriptions.

We determined the frequency and percentage of patients receiving dosages below or above the recommended range, overall, and for users of each particular atypical antipsychotic agent. The frequency and percentage of patients receiving below- or above-range dosages were stratified by gender and age group (seniors versus those younger than 65 years). Differences in the proportions of males and females receiving off-label dosages was evaluated through cross-tabulation, and the statistical significance between differences in these proportions

\begin{tabular}{l|c|c|c|c|c|c|c}
\hline TABLE 1 & Frequency and Percentage of Use of \\
Antipsychotic Medications Within a \\
Medicaid Population: Overall Use and \\
Use of Polytherapy, Stratified by Gender \\
and Age Group
\end{tabular}

* Received at least 3 dispensings for an oral antipsychotic medication during 2003. $\dagger$ Polytherapy $=$ concomitant use of 2 or more different antipsychotic medications.

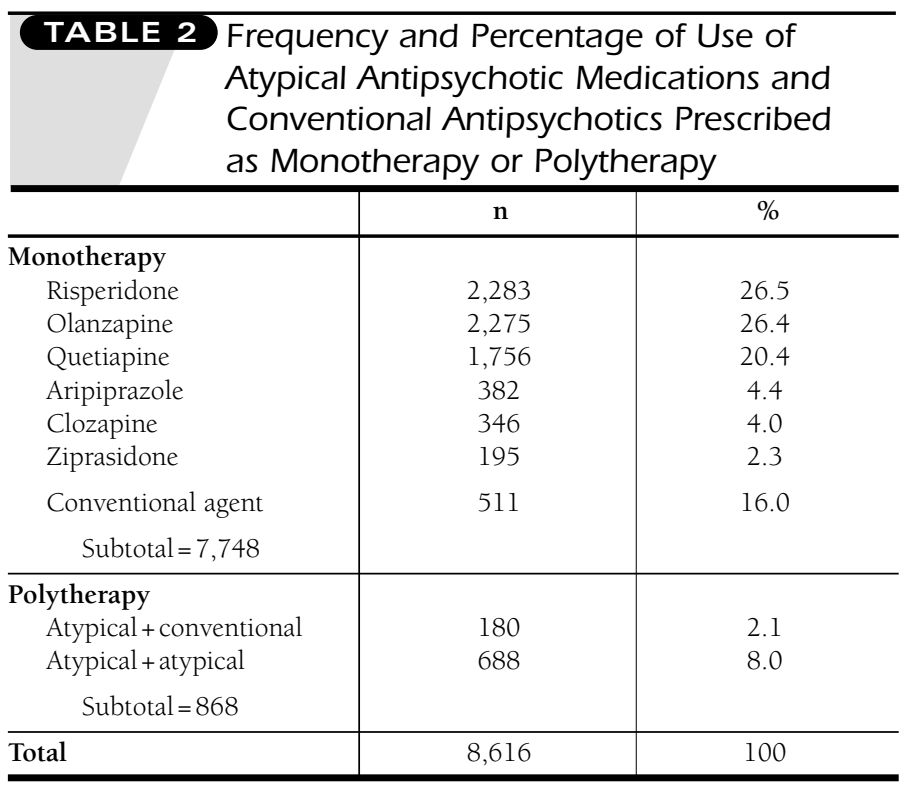

was determined using the chi-square test. Differences in the proportion of senior and nonsenior patients receiving off-label dosages were assessed in the same manner. The level of significance was set at $P<0.05$, with a minimum of 5 observations per cell required for reporting probabilities. These analyses were performed using SAS version 8.1 for microcomputers.

\section{Results}

Of the 59,498 Medicaid fee-for-service program enrollees receiving prescription medication during 2003, nearly 1 in 5 received a dispensing for an antipsychotic medication. A total of 


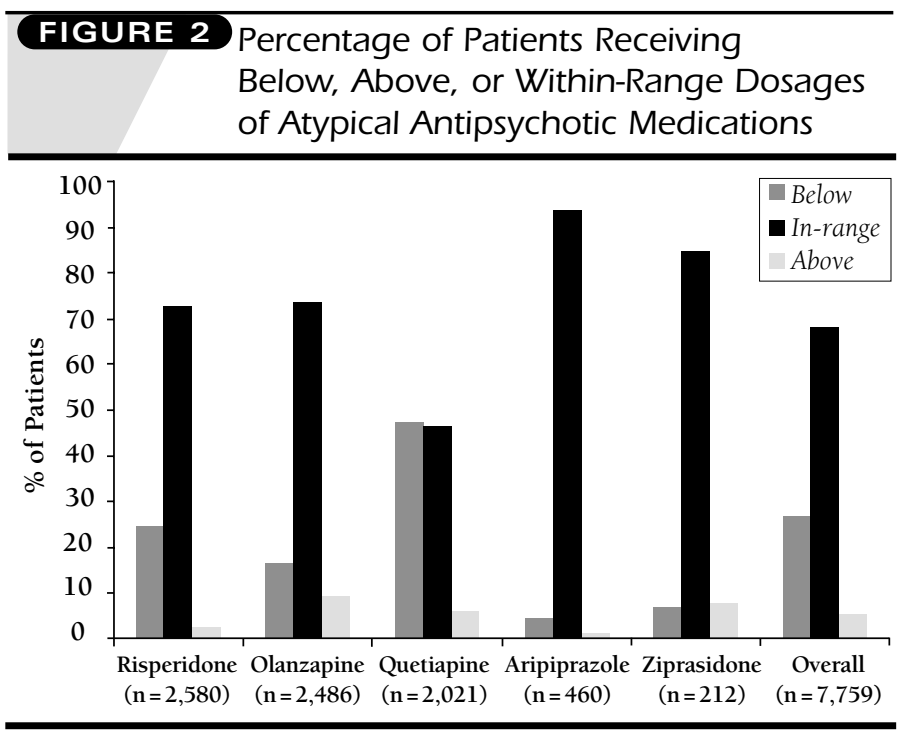

FIGURE 3 Percentage of Patients Receiving AboveRange Dosages of Atypical Antipsychotic Medications: Results Presented by Age Group and Gender

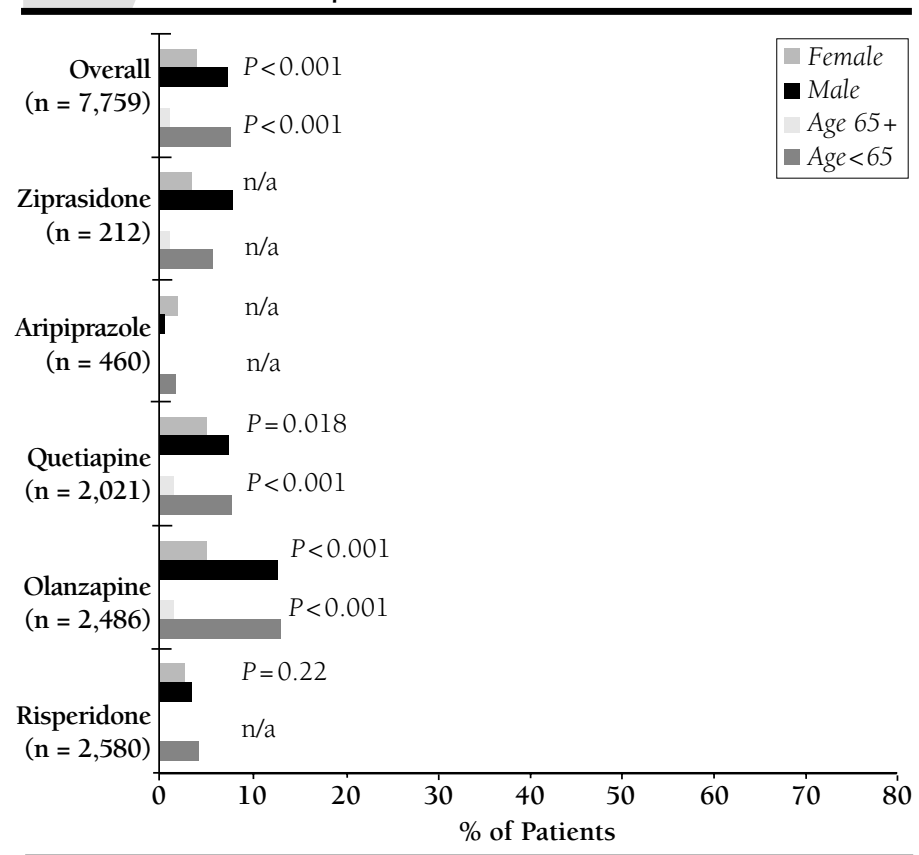

$n / a=$ numbers too small for reporting results of statistical test $(n<5)$.

In-range dosages for aripiprazole: 10-30 mg, quetiapine: 150-750 mg, olanzapine: 5-20 mg, risperidone: 1-8 $\mathrm{mg}$, and ziprasidone: 14-160 $\mathrm{mg}$.

8,616 patients met our criteria of receiving at least 3 dispensings for any oral, nonliquid antipsychotic medication during the year, a majority of which were nonsenior adults (64\%). The use of polytherapy with multiple antipsychotic agents was more frequent among males for both polytherapy with atypical or conventional agents. The use of polytherapy was also more frequent among nonsenior adults than among seniors (13\% versus $5 \%$ ). These results are presented in Table 1.

Of the patients meeting our study criteria, 7,748 (90\%) were identified as receiving monotherapy with an antipsychotic medication, and 7,327 (94\%) of these patients were receiving monotherapy with an atypical antipsychotic medication. Approximately three quarters of patients receiving antipsychotic medication were users of monotherapy with risperidone, olanzapine, or quetiapine. Of the approximately $10 \%$ of patients identified as receiving polytherapy, the majority (688 of 868 , or $79.3 \%$ ) received 2 atypical antipsychotic drugs, while $2.1 \%$ of all patients received polytherapy with an atypical plus a conventional antipsychotic medication $(21 \%$ of patients who received polytherapy) (Table 2 )

Figure 2 presents dose range categories for the prescribed dosages of atypical antipsychotic medications regardless of whether the medication was used alone or in polytherapy with another antipsychotic agent. Overall, approximately 1 in 3 patients was prescribed an atypical antipsychotic medication at a dosage that was not within the recommended range. The majority of off-label dosing was for below-range dosages, as $27 \%$ of patients received medication at a dosage that was below the range recommended in the product labeling. In-range dosing was more frequent among users of aripiprazole (94\%) and ziprasidone $(85 \%)$ as compared with the other atypical antipsychotic medications. Quetiapine was prescribed within the recommended range least frequently; users of this medication received below-range dosages as frequently as they received in-range dosages (47\%). Use of below-range dosages was next most frequent among users of risperidone (25\%) and then olanzapine (17\%), with $7 \%$ of ziprasidone users and $5 \%$ of aripiprazole users receiving below-range dosages.

Use of above-range dosages was much less frequent than the use of below-range dosages. Overall, $6 \%$ of patients received medication at dosages that were higher than recommended in the product labeling. The percentage of patients receiving aboverange dosages was $9.5 \%$ for olanzapine, $8 \%$ for ziprasidone, $6 \%$ for quetiapine, $3 \%$ for risperidone, and $2 \%$ for aripiprazole.

For patients receiving above- or below-range dosages, we determined if the use of such dosages was more frequent among particular age groups or by gender. These stratifications are presented for those receiving above- and below-range dosages in Figures 3 and 4, respectively. Patients receiving above-range dosages were overall more frequently male and younger than 65 years $(P<0.001$ for both). Male and nonelderly patients were also more frequently prescribed above-range dosages of olanzapine and quetiapine as compared with female or senior patients, respectively. Each of these findings was statistically significant. The use of above-range dosages of risperidone, ziprasidone, or aripiprazole did not differ in statistical significance among age 
groups or by gender, though in most cases these subgroups were too small to analyze.

In contrast to patients receiving above-range dosages of these medications, users of below-range dosages were more frequently female and above age 65 years $(P<0.001$ for both). Quetiapine, the agent most frequently prescribed in below-range dosages, was prescribed in below-range dosages for $72.5 \%$ of seniors using this medication. While seniors were more frequently prescribed below-ranges dosages of quetiapine as compared with nonsenior patients $(72.5 \%$ versus $40 \%, P<0.001)$, the percentage of males (47\%) and females (50\%) prescribed below-range dosages of this medication did not differ in statistical significance. For each of the atypical antipsychotics, seniors were more frequently prescribed below-range dosages than nonsenior patients, though the percentage of use of belowrange dosages among seniors varied considerably among medications. Slightly more than half of senior patients (51\%) receiving risperidone were prescribed a dosage that was below the recommended range. This proportion was substantially greater than the percentage of below-range dosages prescribed for seniors using ziprasidone (21\%) or aripiprazole (12\%). Use of below-range dosages of quetiapine, ziprasidone, and aripiprazole was similar among males and females, while females were more likely than males to receive below-range dosages of olanzapine or risperidone $(P<0.001$ for both findings).

\section{Discussion}

In this population of Medicaid-enrolled seniors and disabled patients, we found a high rate of prescribing of antipsychotic medications in off-label dosages. Most of such prescribing was for dosages below the recommended range, though approximately $6 \%$ of patients received dosages that were above the range recommended in the product labeling.

As may be expected, seniors were more frequently prescribed below-range dosages, while above-range dosages were more frequently prescribed for nonsenior patients. This trend, observed for all of the atypical antipsychotic agents prescribed, may likely be mainly attributed to the condition for which the medications were prescribed. It is probable that younger patients were more frequently prescribed these medications for the treatment of schizophrenia or bipolar disorder, while older patients may have more frequently received these medications for off-label conditions such as psychosis or agitation, where lower dosages are commonly prescribed. We note, however, that we did not possess information describing patient diagnoses, and, hence, this interpretation is largely speculative. While we did not examine diagnosis codes to attempt to determine the conditions for which these medications were prescribed, our primary objective was to quantify the extent of off-label dosing regardless of the condition being treated. Furthermore, the reliability of using diagnosis codes from medical claims to identify schizophrenia and related disorders may be questionable..$^{28,29}$

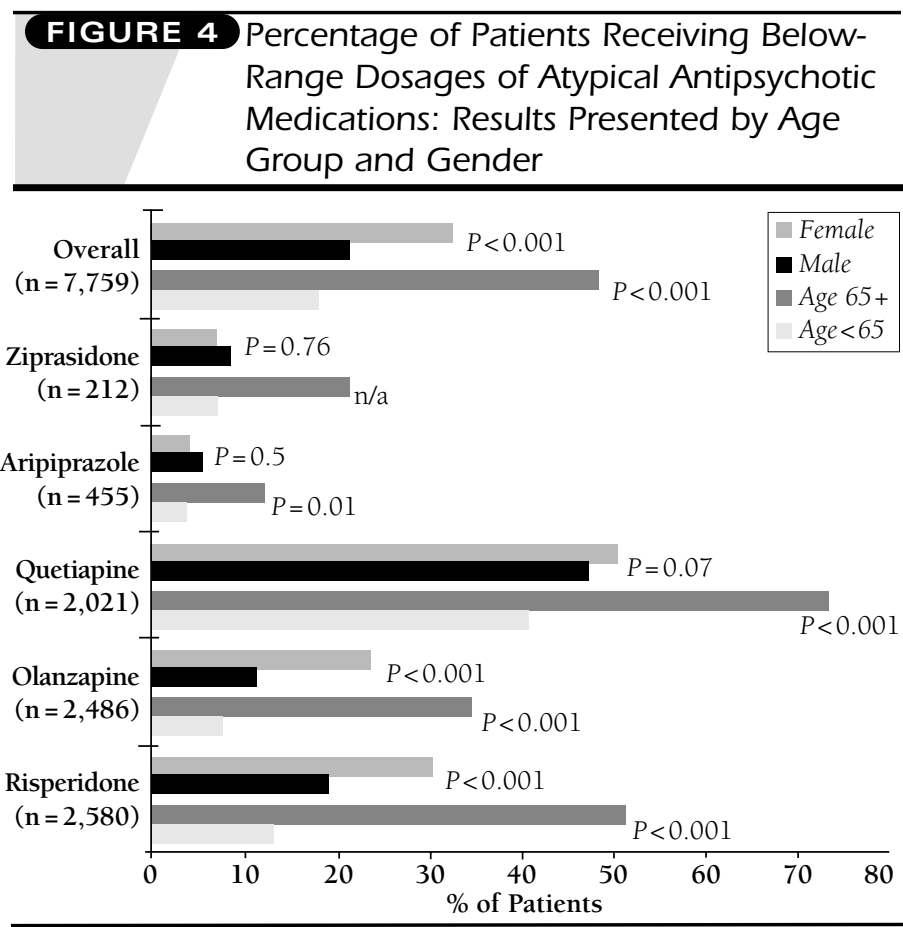

In-range dosages for aripiprazole: 10-30 $\mathrm{mg}$, quetiapine: $150-750 \mathrm{mg}$, olanzapine: 5-20 mg, risperidone: 1-8 $\mathrm{mg}$, and ziprasidone: $14-160 \mathrm{mg}$.

Though not specifically recommended in the product labeling or in current treatment guidelines for schizophrenia ${ }^{30}$ or bipolar disorder, ${ }^{31}$ the use of polytherapy with multiple atypical antipsychotic medications has been identified as an increasingly common practice. ${ }^{15,17,32,33}$ Thus, we were not surprised to find that many patients were receiving multiple antipsychotic medications concomitantly. Indeed, the use of antipsychotic polytherapy was quite common in the population, particularly among younger patients. Roughly 1 in 10 nonelderly patients received therapy with multiple atypical antipsychotics. It is possible that some of these patients were transitioning to different therapies, though we did attempt to exclude patients who were switching therapy, as described above.

Though several reports from smaller trials provide evidence to support the potential effectiveness of antipsychotic polytherapy for patients with treatment-resistant disease, ${ }^{21,22,34}$ no atypical antipsychotic has gained FDA approval for use in combination with other atypicals. Furthermore, the American Psychiatric Association's treatment guidelines for schizophrenia ${ }^{30}$ do not support the use of polytherapy as routine practice. While the use of antipsychotic polytherapy was found to be fairly common in the population studied here, limited information is available regarding the safety of using multiple antipsychotic medications concomitantly. When used as monotherapy, these agents are known to cause potentially significant adverse effects. Many of these agents have been found to increase plasma glucose levels, ${ }^{35}$ 
body weight, ${ }^{36-38}$ and serum triglycerides..$^{39-42}$ The atypical antipsychotic medications are associated with other problematic side effects. To varying degrees, these agents can cause sedation, anticholinergic side effects, ${ }^{43}$ and QTc prolongation. ${ }^{44}$ However little is known about the prevalence and severity of these side effects when atypicals are used in greater than recommended dosages or in combination with each other. At the very least, the benefit-to-risk ratio should be reconsidered when polytherapy is initiated. However, there is a paucity of larger and long-term clinical trials of the use of antipsychotic medications in higher dosages or in combination.

While high doses of atypical antipsychotic agents may be incrementally effective for treatment-resistant patients, the evidence supporting this use is primarily drawn from smaller studies that do not adequately assess the frequency and extent of adverse events likely to be experienced. For example, Lerner et $a . .^{25}$ describes the effectiveness of high-dose olanzapine as prescribed for 3 patients with treatment-resistant schizophrenia, while Brotman et al. ${ }^{26}$ presents a case series of 8 patients receiving high-dose therapy. High-dose therapy may be a useful option for selected patients, yet the relative lack of information pertaining to the safety of such dosages is of concern. It was encouraging in our study to find a small percentage of elderly patients (less than $1 \%$ ) who received higher dosages of antipsychotic medications, but nearly $8 \%$ of nonelderly patients received atypical antipsychotic medication in dosages above the recommended range. This suggests that the use of high-dose therapy in younger adult patients is fairly common, at least within this Medicaid subpopulation.

Though the use of below-range dosages may be of lesser concern in terms of the safety and risks of therapy, one may question the rationale for using these medications in potentially subtherapeutic dosages. The in-range dosages applied in our analyses included dosages recommended for frail and elderly patients. As such, patients identified as using below-range dosages were prescribed medication in dosages that were below what was found to be efficacious in the clinical trials upon which the FDA-approved labeling is based (though such trials generally do not include frail and/or elderly patients). Perhaps prescribers were merely exerting caution when using these agents in elderly patients. Lower dosages of atypical antipsychotics are associated with a reduced incidence of motoric side effects such as tardive dyskinesia, ${ }^{45}$ but placebo-controlled trials demonstrating the efficacy of low-dose therapy in the treatment of schizophrenia or bipolar disease are lacking.

It is possible that many elderly patients in the population we studied received these medications in low dosages for off-label indications such as agitation or insomnia. This may be particularly true for the use of quetiapine, which was prescribed in below-range dosages for nearly 3 of 4 seniors receiving this medication. We also considered the possibility that patients receiving low-dose therapy may have been more likely to be users of polytherapy. However we found the converse to be truepatients prescribed below-range dosages of atypical antipsychotics were less likely to be receiving multiple antipsychotic agents than were users of higher dosages ( $6 \%$ versus $13 \%, P<0.001$ ).

Overall, these findings provide evidence that the FDA-approved labeling describing the indications and recommended dosages of these agents appears to correspond poorly with how atypical antipsychotics are prescribed in practice. Yet it is important to note that our findings do not necessarily indicate that medications were prescribed inappropriately. It may be argued that the off-label use of medications reflects emerging knowledge and that the product labeling may fail to keep pace with new findings pertaining to the scope or utility of medications.

The FDA's supplemental new drug approval (sNDA) process provides a mechanism for updating the product labeling to include new indications and updated dosages. However, the costs associated with the submission of an sNDA may present a disincentive to manufacturers, especially when a new indication or dosage pertains to a smaller subpopulation of potential medication users. Furthermore, the efficacy of the medication for a new use or dosage may fail to be substantiated when subjected to the rigorous study required for submission of an SNDA, creating a disincentive for manufacturers to submit such an application. The need for a manufacturer to obtain an SNDA is lessened further when physicians rely upon personal experience and the opinions of others when prescribing medications. Thus, at least partially as a consequence of the above considerations, there exists a complex dynamic between the FDA-approved usage of a medication versus published evidence from recent trials and experience gained from prescribing a medication in practice.

The off-label prescribing of these medications presents important issues from the perspectives of the practicing pharmacist and for those responsible for the pharmacy benefit. The practicing pharmacist must be aware that the risks described in the product labeling directly pertain to the use of the medications for approved indications and when prescribed at recommended dosages. The use of polytherapy with multiple antipsychotic medications or the prescribing of above-range dosages warrants careful consideration of the potential for benefits and risks. The dispensing pharmacist can provide a service to prescribers and other members of the health care team by making them aware of patient cases in which the prescribed therapy is considered to be off-label and by alerting providers to the need for increased attention to monitoring for effectiveness and signs of adverse reactions.

The implications for those responsible for providing the pharmacy benefit are less straightforward. The atypical antipsychotics are an expensive class of medications, but these drugs have become common in the care for patients with psychosis, and can be cost effective when used appropriately. How then should these medications be used most appropriately within a population? Some may interpret "appropriate use" as the prescribing of these products only for labeled indications 
and at recommended dosages. Formulating policy upon such an interpretation may prove to be difficult given the extent of off-label usage as described here and by others. Most importantly, such a policy is not likely to benefit patients when off-label uses offer a therapeutic advantage. Nevertheless, one may question if the pharmacy benefit should provide for the use of expensive therapies that have not been assessed for safety and effectiveness. The use of such therapies may be justified where off-label regimens benefit patients more than they harm them, but it is often not possible to know a priori when this might be the case.

Analyses such as the type described here can provide the basis for interventions designed to align prescribing within appropriate dosing parameters, as determined through review of the available evidence, and by collaborating with clinicians having expertise in the use of these medications. Such interventions may potentially include provider profiling, academic detailing, or other educational initiatives designed to inform prescribers about the risks and benefits of the off-label use of these medications.

Another approach is to require that appropriate diagnoses exist prior to initial prescription. Policy makers must be careful when developing criteria for such a strategy, since the use of atypical antipsychotic medications for off-label conditions may offer a meaningful therapeutic benefit for certain patients.

Lastly, we note that on-screen edits alerting the pharmacist to the prescribing of off-label dosages can be helpful for identifying dosage errors and prompting the pharmacist to contact the prescriber to ensure that the proper medication dosage is prescribed. While the prescriber may ultimately decide which medication dosage is employed, a clinically sound and well-managed system for utilizing these medications within the parameters of the pharmacy benefit will aid in ensuring that the inappropriate use of these medications is minimized.

\section{Limitations}

Our research included several limitations that should be acknowledged. Most important, pharmacy claims were our sole data source, and we did not determine the conditions for which these medications were prescribed. It is possible that our results may be biased by inaccuracies in the pharmacy claims data. For example, since we did not audit or otherwise verify the dosages of medication prescribed (e.g., through review of medical charts), it is possible that inaccurate values in pharmacy claims for the days supply or quantity of medication dispensed were a source of error. Also, we did not determine the duration of use of these medications and dosages.

Though our inclusion criteria specified that patients must have received at least 3 dispensings of antipsychotic medication, it is possible that some patients receiving below-range dosages would have eventually been titrated upward to an in-range dosage.

Additionally, we did not examine other factors that may have further explained our findings. For example, dosReis et al. ${ }^{18}$ found that African-American Medicaid enrollees more frequently received higher dosages of antipsychotic medications than other racial groups, while Galletly and Tsourtos found that schizophrenic patients receiving lithium, carbamazepine, or benzodiazepines were more likely to receive higher dosages of antipsychotic medications. ${ }^{46}$

Finally, we should note that our findings apply only to this population of aged or disabled Medicaid enrollees. Generalizations to other populations should be made with caution.

\section{Conclusion}

In this subpopulation of Medicaid enrollees, we found that many patients (33\%) were prescribed atypical antipsychotic medications in off-label dosages, and many patients (10\%) received multiple antipsychotic medications. These findings suggest that physicians commonly prescribe antipsychotic medications in a manner that differs from the recommendations described in the prescribing information. Pharmacists have an important role in working with the health care team to ensure that the risks and benefits associated with the off-label use of antipsychotic medications are carefully considered and that patients are appropriately monitored. From a policy perspective, the off-label use of atypical antipsychotic medications raises important questions regarding the purpose and applicability of the product labeling, particularly in the context of current prescribing practices.

\section{ACKNOWLEDGMENTS}

The authors would like to thank Paula Avarista, MBA, RPh, chief of pharmacy and related services of the Rhode Island Medicaid Pharmacy Program. She was instrumental in facilitating the collaboration between the College of Pharmacy and the R.I. Department of Human Services and in obtaining the data for this research. Avarista also served as preceptor for author Felix Yam, who was a pharmacy student during the origin of this project. We also thank Richard Wagner, MD, medical director, Behavioral Health Sciences, R.I. Department of Mental Health, Retardation and Hospitals, Cranston, who reviewed our manuscript and provided helpful comments.

\section{DISCLOSURES}

No outside funding supported this study. Authors Stephen J. Kogut and Felix Yam disclose no potential bias or conflict of interest relating to this article; author Robert Dufresne discloses that he participates in the speakers bureau of or is an advisor to the boards of Eli Lilly and Company, Janssen Pharmaceutica, AstraZeneca, Bristol-Myers Squibb Company, and Abbott Laboratories. Kogut served as principal author of the study. Study concept and design were contributed by Kogut and Yam. Analysis and interpretation of data and statistical expertise were contributed by all authors. Drafting of the manuscript was primarily the work of Kogut, and its critical revision was the work of all authors. Administrative, technical, and/or material support was provided by Paula Avarista (see Acknowledgments).

\section{REFERENCES}

1. Revicki DA. Cost-effectiveness of the newer atypical antipsychotics: a review of the pharmacoeconomic research evidence. Curr Opin Investig Drugs. 2001;2:110-17.

2. Gibson PJ, Damler R, Jackson EA, Wilder T, Ramsey JL. The impact of olanzapine, risperidone, or haloperidol on the cost of schizophrenia care in a Medicaid population. Value Health. 2004;7:22-35.

3. Jerrell JM. Cost-effectiveness of risperidone, olanzapine, and conventional antipsychotic medications. Schizophr Bull. 2002;28:589-605. 
4. Almond S, O'Donnell O. Cost analysis of the treatment of schizophrenia in the UK. A simulation model comparing olanzapine, risperidone and haloperidol. Pharmacoeconomics. 2000;17:383-89.

5. Galvin PM, Knezek LD, Rush AJ, Toprac MG, Johnson B. Clinical and economic impact of newer versus older antipsychotic medications in a community mental health center. Clin Ther. 1999;21:1105-16.

6. Leucht S, Pitschel-Walz G, Abraham D, Kissling W. Efficacy and extrapyramidal side-effects of the new antipsychotics olanzapine, quetiapine, risperidone, and sertindole compared to conventional antipsychotics and placebo. A meta-analysis of randomized controlled trials. Schizophr Res. 1999;35:51-68.

7. Correll CU, Leucht S, Kane JM. Lower risk for tardive dyskinesia associated with second-generation antipsychotics: a systematic review of 1-year studies. Am J Psychiatry. 2004;161:414-25.

8. Volavka J, Czobor P, Sheitman B, et al. Clozapine, olanzapine, risperidone, and haloperidol in the treatment of patients with chronic schizophrenia and schizoaffective disorder. Am J Psychiatry. 2002;159:255-62.

9. Barak Y, Shamir E, Zemishlani H, Mirecki I, Toren P, Weizman R. Olanzapine versus haloperidol in the treatment of elderly chronic schizophrenia patients. Prog Neuropsychopharmacol Biol Psychiatry. 2002;26:1199-202.

10. Gomez JC, Crawford AM. Superior efficacy of olanzapine over haloperidol: analysis of patients with schizophrenia from a multicenter international trial. J Clin Psychiatry. 2001;62(suppl 2):6-11.

11. Ritchie CW, Chiu E, Harrigan S, et al. The impact upon extra-pyramidal side effects, clinical symptoms and quality of life of a switch from conventional to atypical antipsychotics (risperidone or olanzapine) in elderly patients with schizophrenia. Int J Geriatr Psychiatry. 2003;18:432-40.

12. Hamilton SH, Revicki DA, Genduso LA, Beasley CM Jr. Olanzapine versus placebo and haloperidol: quality of life and efficacy results of the North American double-blind trial. Neuropsychopharmacology. 1998;18:41-49.

13. Revicki DA, Genduso LA, Hamilton SH, Ganoczy D, Beasley CM Jr. Olanzapine versus haloperidol in the treatment of schizophrenia and other psychotic disorders: quality of life and clinical outcomes of a randomized clinical trial. Qual Life Res. 1999;8:417-26.

14. Palmer CS, Brunner E, Ruiz-Flores LG, Paez-Agraz F, Revicki DA. A cost-effectiveness clinical decision analysis model for treatment of schizophrenia. Arch Med Res. 2002;33:572-80.

15. Schumacher JE, Makela EH, Griffin HR. Multiple antipsychotic medication prescribing patterns. Ann Pharmacother. 2003;37:951-55.

16. Tapp A, Wood AE, Secrest L, Erdmann J, Cubberley L, Kilzieh N. Combination antipsychotic therapy in clinical practice. Psychiatr Serv. 2003;54:55-59.

17. Procyshyn RM, Kennedy NB, Tse G, Thompson B. Antipsychotic polypharmacy: a survey of discharge prescriptions from a tertiary care psychiatric institution. Can J Psychiatry. 2001;46:334-39.

18. dosReis S, Zito JM, Buchanan RW, Lehman AF. Antipsychotic dosing and concurrent psychotropic treatments for Medicaid-insured individuals with schizophrenia. Schizophr Bull. 2002;28:607-17.

19. Walkup JT, McAlpine DD, Olfson M, Labay LE, Boyer C, Hansell S. Patients with schizophrenia at risk for excessive antipsychotic dosing. J Clin Psychiatry. 2000;61:344-48.

20. Collins EJ, Hogan TP, Awad AG. The pharmacoepidemiology of treatmentrefractory schizophrenia. Can J Psychiatry. 1992;37:192-95.

21. Lerner V, Chudakova B, Kravets S, Polyakova I. Combined use of risperidone and olanzapine in the treatment of patients with resistant schizophrenia: a preliminary case series report. Clin Neuropharmacol. 2000;23:284-86.

22. Lerner V, Libov I, Kotler M, Strous RD. Combination of "atypical" antipsychotic medication in the management of treatment-resistant schizophrenia and schizoaffective disorder. Prog Neuropsychopharmacol Biol Psychiatry. 2004;28:89-98.
23. Freudenreich O, Goff DC. Antipsychotic combination therapy in schizophrenia. A review of efficacy and risks of current combinations. Acta Psychiatr Scand. 2002;106:323-30.

24. Duggal HS. Aripirazole-olanzapine combination for treatment of schizophrenia. Can J Psychiatry 2004:49:151.

25. Lerner V. High-dose olanzapine for treatment-refractory schizophrenia. Clin Neuropharmacol. 2003;26:58-61.

26. Brotman AW, McCormick S III. A role for high-dose antipsychotics. J Clin Psychiatry. 1990;51:164-66.

27. Kinon BJ, Ahl J, Stauffer VL, Hill AL, Buckley PF. Dose response and atypical antipsychotics in schizophrenia. CNS Drugs. 2004;18:597-616.

28. Bertelsen A. Schizophrenia and related disorders: experience with current diagnostic systems. Psychopathology. 2002;35:89-93.

29. Hiller W, Dichtl G, Hecht H, Hundt W, von Zerssen D. Testing the comparability of psychiatric diagnoses in ICD-10 and DSM-III-R. Psychopathology. 1994;27:19-28.

30. Lehman AF, Lieberman JA, Dixon LB, et al. Practice guideline for the treatment of patients with schizophrenia. 2nd. ed. Am J Psychiatry. 2004;161:1-56.

31. Practice guideline for the treatment of patients with bipolar disorder (revision). Am J Psychiatry. 2002;159:1-50.

32. McCue RE, Waheed R, Urcuyo L. Polypharmacy in patients with schizophrenia. J Clin Psychiatry. 2003;64:984-89.

33. Clark RE, Bartels SJ, Mellman TA, Peacock WJ. Recent trends in antipsychotic combination therapy of schizophrenia and schizoaffective disorder: implications for state mental health policy. Schizophr Bull. 2002;28:75-84.

34. Zink M, Mase E, Dressing H. Combination of ziprasidone and clozapine in treatment-resistant schizophrenia. Hum Psychopharmacol. 2004;19:271-73.

35. Lindenmayer JP, Czobor P, Volavka J, et al. Changes in glucose and cholesterol levels in patients with schizophrenia treated with typical or atypical antipsychotics. Am J Psychiatry. 2003;160:290-96.

36. Ganguli R, Brar JS, Ayrton Z. Weight gain over 4 months in schizophrenia patients: a comparison of olanzapine and risperidone. Schizophr Res. 2001;49: 261-67.

37. Volavka J, Czobor P, Sheitman B, et al. Clozapine, olanzapine, risperidone, and haloperidol in the treatment of patients with chronic schizophrenia and schizoaffective disorder. Am J Psychiatry. 2002;159:255-62.

38. Henderson DC, Cagliero E, Gray C, et al. Clozapine, diabetes mellitus, weight gain, and lipid abnormalities: A five-year naturalistic study. Am J Psychiatry. 2000;157:975-81.

39. Ghaeli P, Dufresne RL. Serum triglyceride levels in patients treated with clozapine. Am J Health. Syst Pharm 1996;53:2079-81.

40. Gaulin BD, Markowitz JS, Caley CF, Nesbitt LA, Dufresne RL. Clozapineassociated elevation in serum triglycerides. Am J Psychiatry. 1999;156: 1270-72.

41. Kinon BJ, Basson BR, Gilmore JA, Tollefson GD. Long-term olanzapine treatment: weight change and weight-related health factors in schizophrenia. J Clin Psychiatry. 2001;62:92-100.

42. Osser DN, Najarian DM, Dufresne RL. Olanzapine increases weight and serum triglyceride levels. J Clin Psychiatry. 1999;60:767-70.

43. Adverse effects of the atypical antipsychotics. Collaborative Working Group on Clinical Trial Evaluations. J Clin Psychiatry. 1998;59:17-22.

44. Harrigan EP, Miceli JJ, Anziano R, et al. A randomized evaluation of the effects of six antipsychotic agents on QTc, in the absence and presence of metabolic inhibition. J Clin Psychopharmacol. 2004;24:62-69.

45. Jeste DV. Tardive dyskinesia rates with atypical antipsychotics in older adults. J Clin Psychiatry. 2004;65:21-24.

46. Galletly CA, Tsourtos G. Antipsychotic drug doses and adjunctive drugs in the outpatient treatment of schizophrenia. Ann Clin Psychiatry. 1997;9:77-80. 